\title{
Assessment of Left Ventricular Mechanical Function in Cardiac Syndrome X: Speckle Tracking Imaging Study
}

\author{
Mahmoud Kamel, Ahmed Emara, Said Shalaby Montaser, Mahmoud Said \\ Menufia University Hospital, Shibin El Kom, Egypt \\ Email:mahmoudkamel35@gmail.com,am.emara@yahoo.com, saidshalaby@yahoo.com,mahmoud.k.g@hotmail.com
}

How to cite this paper: Kamel, M., Emara, A., Montaser, S.S. and Said, M. (2018) Assessment of Left Ventricular Mechanical Function in Cardiac Syndrome X: Speckle Tracking Imaging Study. World Journal of Cardiovascular Diseases, 8, 557-568. https://doi.org/10.4236/wjcd.2018.812055

Received: November 1, 2018

Accepted: December 21, 2018

Published: December 24, 2018

Copyright (c) 2018 by authors and Scientific Research Publishing Inc. This work is licensed under the Creative Commons Attribution International License (CC BY 4.0).

http://creativecommons.org/licenses/by/4.0/

\begin{abstract}
Objective: Early detection of LV mechanical abnormalities in patients with cardiac syndrome X (CSX) by speckle tracking echocardiography (STE). Background: Cardiac syndrome $\mathrm{X}$ is a triad of angina pectoris, positive stress test for myocardial ischemia and angiographically free coronary arteries. Two dimensional speckle tracking echocardiography (2D-STE) provides a more sensitive method for evaluation of global and segmental LV function than conventional two dimensional echocardiographic parameters. Subjects and Methods: Seventy patients proved to have CSX and 20 healthy control volunteers were included with a mean age of $49.43 \pm 5.92$ vs. $49.40 \pm 6.27$ years respectively with no difference regarding sex for both patients and controls. Patients with hypertension, diabetes mellitus, valvular heart disease, cardiomyopathies, inflammatory diseases, myocarditis and arrhythmias were excluded. All included individuals were subjected to complete conventional echocardiographic assessment and left ventricular global and segmental mechanical function was assessed using $2 \mathrm{D}$ based strain and strain rate (longitudinal, radial and circumferential) imaging. Results: There was no statistically significant difference in LV conventional echo parameters between patients and controls. However, global mean longitudinal strain was significantly lower in patients than controls $(-15.05 \pm 3.28$ vs. $-20.22 \pm 2.49$; $\mathrm{p}<0.001)$. For radial and circumferential strain stain, there was no significant changes between patients vs. controls $(29.75 \pm 18.26$ vs. $28.09 \pm 15.48 ; \mathrm{p}=0.74)$ and $(-19.88 \pm 8.63$ vs. $-21.93 \pm 5.69 ; \mathrm{p}<0.05)$ respectively. Conclusion: In spite of normal conventional echo parameters among patients and controls, LV longitudinal strain and strain rate by $2 \mathrm{D}$ speckle tracking imaging were lower in the patients denoting subclinical left ventricular mechanical dysfunction in patients with CSX.
\end{abstract}




\section{Keywords}

Cardiac Syndrome X, Left Ventricular Systolic and Diastolic Function, 2D-Speckle Tracking Strain and Strain Rate Imaging

\section{Introduction}

Cardiac syndrome $\mathrm{X}$ is a triad of angina pectoris, positive stress test for myocardial ischemia and angiographically free coronary arteries. Although syndrome $\mathrm{X}$ patients have a better cardiovascular prognosis than patients with classical coronary arteries stenosis, patients can suffer from incapacitating and agonizing chest pain which robs them of their quality of life [1]. While various avenues of research have been undertaken in order to more widely explore the symptoms associated with syndrome $\mathrm{X}$, there are no definitive conclusions as regards the exact pathogenesis of the condition [2].

Endothelial dysfunctions, microvascular dysfunction with coronary microvascular spasms, abnormal coronary vascular resistance, and subendocardial ischemia have been recognized as possible pathophysiologic mechanisms [3].

Several studies have found myocardial perfusion abnormalities in patients with CSX using positron emission tomography [4], scintigraphic myocardial perfusion imaging [5], and nuclear magnetic resonance imaging [6]. Although left ventricular (LV) diastolic dysfunction has been shown in studies using conventional and tissue Doppler echocardiography, LV systolic function was found to be normal [7] [8].

Two-dimensional speckle tracking imaging is an adequate method for assessing left ventricular mechanical function and detecting subclinical dysfunction. Being angle-independent allows two dimensional measurement of deformation. Speckle tracking derived strain and strain rate were more accurate and reproducible than Doppler tissue imaging derived strain and strain rate. Good-quality grey scale image is mandatory for speckle tracking measurement [9].

The study aims to assess LV mechanical function in patients with CSX by STE for early recognition of LV subclinical abnormalities.

\section{Patients and Methods}

1) Patient Selection

We prospectively examined 90 individuals (70 patient proved to have cardiac syndrome X (group I) and 20 age and sex matched healthy volunteers as a controls (group II) selected from Cardiology department Menoufia University Hospital during the period between April 2014, and June 2016.

They were enrolled in the study after obtaining their written informed consent, and approval of Ethics Committee of Menoufia university hospital. Patient's inclusion criteria were, typical angina, a positive exercise stress test (Stress E.C.G., Doubutamine stress Echo or Myocardial Perfusion Imaging), and angio- 
graphically normal coronary arteries. Exclusion criteria for both groups were diabetes mellitus, hypertension, inflammatory diseases, primary valvular heart disease, cardiomyopathies, myocarditis, arrhythmias, and angiographically documented significant coronary arteries lesions. Stress ECG was done for all control group and we excluded those with positive results.

2) Conventional echocardiographic examination was done using the commercially available Vivid 9, GE Vingmed, Norway equipped with a $1.7-4 \mathrm{MHz}$ phased-array transducer. Echocardiographic imaging was obtained in the parasternal short and long axis, and apical 4.2 and 3-chamber views using standard transducer positions. LV end-diastolic \& systolic diameters, posterior wall and septal walls thickness, ejection fraction and left atrial diameter were measured in accordance with the recommendations of the American Society of Echocardiography [10]. Pulsed and continuous-wave Doppler was used for diastolic function and valvular assessment.

Doppler tissue imaging derived early (e) and late (a), Mitral annular velocity waves were measured from septal annular site in apical four chamber view and the ratio of early mitral flow $\mathrm{E}$ wave to the early annular wave (E/e ratio) was measured.

3) Speckle tracking imaging was used to measure global longitudinal, circumferential and radial Strain (S) and strain rate (SR). From apical 4, 2 and 3 chamber views using frame rate between 40 - 90 or at least $40 \%$ of HR, three consecutive cardiac cycles and another three cycles from the short axis view at the level of the LV papillary muscles were stored for post-processing to measure global longitudinal and both circumferential and radial S and SR respectively.

Then after activation of automated function imaging system (AFI), all data were transported for off-line analysis, using Vivid 9 system Echo Pac, GE Vingmed, Horton, Norway where peak systolic strain (Ssys), peak systolic strain rate (SRsys), early (SRe) \& late diastolic strain rate (SRa) were assessed and measured.

\section{Statistical Analyses}

Using statistical package for the social science software (SPSS) version 16, data from the patients and controls were collected and subjected to statistical analysis.

The level of significance is $95 \%$. So $\mathrm{P}$ value $>0.05$ was considered a non-significant result, $\mathrm{P}$ value $<0.05$ was considered a significant result, and that $<0.001$ was considered a highly significant result.

\section{Results}

The study included 70 patients with CSX, 54\% were female, and $46 \%$ were males) with mean age $49.43 \pm 5.92$ years, 39 patient had positive stress ECG, 14 patients with positive dobutamine stress echo and 17 patients with positive myocardial perfusion imaging, compared to 20 healthy persons, 9 patients were female and 11 were males with mean age $49.40 \pm 6.27$ years. There was no sig- 
nificant statistical difference between both groups as regarding age and sex (Table $1 \&$ Table 2).

There was a non-significant difference between two groups as regards to conventional echocardiographic parameters (LV diastolic and systolic dimension, EF, Doppler derived mitral flow parameters, left atrial \& aortic root diameters. However, there was a significantly lower Doppler tissue imaging derived peak early mitral annular velocity (e') E/e' in group I compared to group II $(\mathrm{P}<0.001$ $\& 0.0009$ respectively) (Table 3 ).

\section{Two D Speckle Tracking Echocardiography}

Global Longitudinal systolic strain and systolic SR were statistically significantly lower in group I than group II ( $\mathrm{P}<0.001$, and $\mathrm{P}<0.005$ respectively) denoting impaired LV longitudinal systolic mechanical function. There was no significant difference among group I and II as regard to global circumferential and radial strain and SR ( $P>0.05$ for both values). This means that there was earlier affection of subendocardial fibers which is the main layer responsible for LV longitudinal systolic function. Global longitudinal, circumferential, radial and early diastolic $\mathrm{E}$ wave SR, were significantly lower in group I compared to group II (P values were $0.001,0.03$ and 0.002 respectively), denoting that $\mathrm{LV}$ diastolic function

Table 1. Comparison of demographic data \& risk factors between both groups.

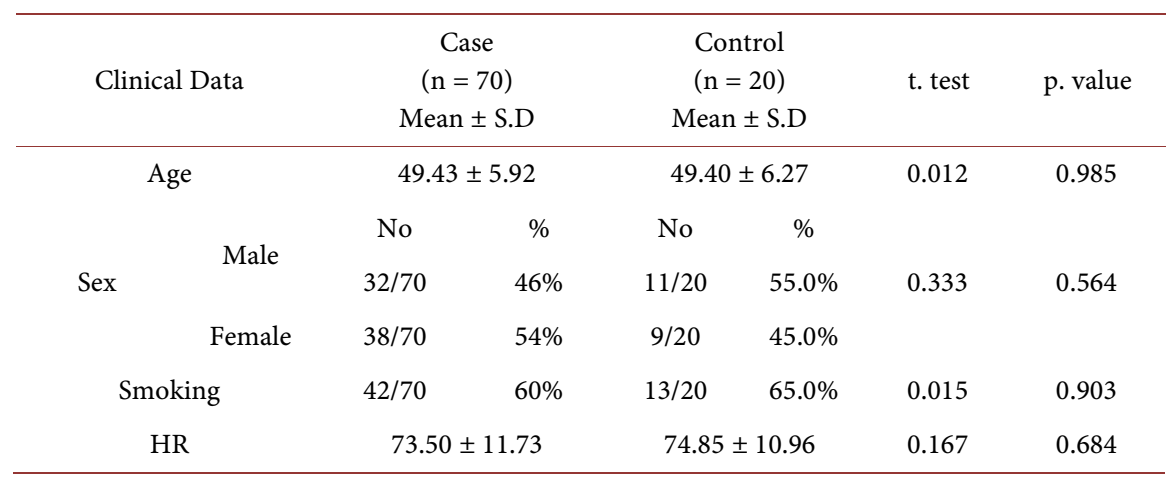

HR: Heart Rate, $\mathrm{P}$-value $\leq 0.05$ is considered significant, $\mathrm{t}=$ student test.

Table 2. Typed of Stress modalities used in diagnosis of ischemia in case group.

\begin{tabular}{ccc}
\hline \multicolumn{2}{c}{ +ve Stress Modality } & \multicolumn{2}{c}{ Case } \\
\hline Stress E.C.G & $\mathrm{N}$ & 39 \\
Stress Echo & $\%$ & $56 \%$ \\
Myocardial Perfusion Image (MPI) & $\mathrm{N}$ & 14 \\
& $\%$ & $20 \%$ \\
Total & $\mathrm{N}$ & 17 \\
& $\%$ & $24 \%$ \\
& $\mathrm{~N}$ & $70 \%$ \\
\hline
\end{tabular}


Table 3. Comparison of conventional Echocardiographic parameters between studied groups.

\begin{tabular}{|c|c|c|c|c|}
\hline Parameter & $\begin{array}{c}\text { Case } \\
\text { Mean } \pm \text { S.D }\end{array}$ & $\begin{array}{c}\text { Control } \\
\text { Mean } \pm \text { S.D }\end{array}$ & t. test & p. value \\
\hline IVSD $(\mathrm{cm})$ & $0.95 \pm 0.18$ & $0.97 \pm 0.21$ & 0.109 & 0.743 \\
\hline IVSs $(\mathrm{cm})$ & $1.34 \pm 0.31$ & $1.34 \pm 0.37$ & 0.003 & 0.959 \\
\hline LVIDd $(\mathrm{cm})$ & $4.95 \pm 0.47$ & $4.99 \pm 0.53$ & 0.060 & 0.807 \\
\hline LVIDs (cm) & $3.21 \pm 0.43$ & $3.19 \pm 0.51$ & 0.016 & 0.901 \\
\hline LVPWd $(\mathrm{cm})$ & $0.97 \pm 0.18$ & $1.02 \pm 0.19$ & 0.623 & 0.434 \\
\hline LVEDV (ml) & $117.10 \pm 27.32$ & $119.30 \pm 31.10$ & 0.070 & 0.793 \\
\hline LVESV (ml) & $42.23 \pm 15.30$ & $42.05 \pm 18.10$ & 0.001 & 0.969 \\
\hline $\mathrm{EF}(\%)$ & $64.57 \pm 6.53$ & $65.60 \pm 7.59$ & 0.264 & 0.610 \\
\hline $\mathrm{SV}(\mathrm{ml})$ & $74.33 \pm 17.97$ & $76.40 \pm 20.35$ & 0.143 & 0.707 \\
\hline FS (\%) & $35.83 \pm 5.36$ & $36.60 \pm 6.26$ & 0.214 & 0.645 \\
\hline $\mathrm{AO}(\mathrm{cm})$ & $2.99 \pm 0.45$ & $3.04 \pm 0.49$ & 0.097 & 0.756 \\
\hline $\mathrm{LA}(\mathrm{cm})$ & $3.99 \pm 0.49$ & $4.11 \pm 0.50$ & 0.686 & 0.412 \\
\hline $\mathrm{LA} \backslash \mathrm{AO}$ & $1.34 \pm 0.21$ & $1.37 \pm 0.22$ & 0.148 & 0.702 \\
\hline E velocity $(\mathrm{cm} / \mathrm{s})$ & $85.78 \pm 17.74$ & $94.95 \pm 16.00$ & 1.859 & 0.069 \\
\hline A velocity $(\mathrm{cm} / \mathrm{s})$ & $76.04 \pm 12.68$ & $79.57 \pm 7.18$ & 1.126 & 0.265 \\
\hline $\mathrm{E} / \mathrm{A}$ & $1.04 \pm 0.26$ & $1.20 \pm 0.20$ & 0.850 & 0.399 \\
\hline$E^{\prime}(\mathrm{cm} / \mathrm{s})$ & $4.07 \pm 3.82$ & $7.81 \pm 1.87$ & 4.129 & $0.001^{*}$ \\
\hline $\mathrm{E} / \mathrm{E}^{\prime}$ & $17.98 \pm 6.01$ & $12.80 \pm 3.12$ & 3.53 & $0.009^{*}$ \\
\hline
\end{tabular}

IVSD: diastolic interventricular septum dimension, IVSS: systolic interventricular septum dimension, LVIDD: left ventricular end diastolic dimension, LVIDS: left ventricular end systolic dimension, LVPWD: left ventricular posterior wall dimension, EDV: end diastolic volume, ESV: end systolic volume, EF: ejection fraction, FS: fractional shortening, SV: stroke Volume, AO: aortic root diameter, LA: left atrium diameter, LA/AO: left atrium diameter to aortic root diameter ratio, E velocity: mitral early velocity, A velocity: mitral late velocity, E': mitral annular early velocity, E/A: mitral early and late velocities ratio, E/E': mitral and mitral annular early velocities ratio, $\mathrm{P}$-value $\leq 0.05$ is considered significant, $\mathrm{t}=$ student test.

was more and extensively affected than systolic function (Table 4 and Table 5, Figure 1-3).

\section{Discussion}

Cardiacsyndrome $\mathrm{X}$ is a combination of anginapectoris, positive stress test for myocardial ischemia and free coronary arteries by coronary angiography [1].

Although there was no significant difference in conventional systolic and diastolic echocardiographic parameters between group I and II, the main finding of this study was, First, detection of a subclinical LV systolic mechanical dysfunction proved by impaired both regional and global longitudinal strain and strain rate among included patients compared to controls. Second, impaired diastolic function proved by impaired early diastolic longitudinal, radial and circumferential SR in CSX group.

Conventional echocardiographic parameters failed to detect significant difference in diastolic and systolic functions among patients compared to controls. 
Table 4. Comparison of LV Strain between both groups.

\begin{tabular}{|c|c|c|c|c|}
\hline LV Wall Strain & $\begin{array}{c}\text { Case } \\
\text { Mean } \pm \text { S.D }\end{array}$ & $\begin{array}{c}\text { Control } \\
\text { Mean } \pm \text { S.D }\end{array}$ & t. test & p. value \\
\hline \multicolumn{5}{|l|}{ Apical 4 view } \\
\hline $\begin{array}{l}\text { Longitudinal Strain of } \\
\text { SEPT wall }\end{array}$ & $-15.21 \pm 5.94$ & $-19.49 \pm 4.81$ & 2.683 & $0.01^{*}$ \\
\hline $\begin{array}{c}\text { Longitudinal Strain of } \\
\text { LAT wall }\end{array}$ & $-15.25 \pm 4.8$ & $-19.88 \pm 3.3$ & 3.74 & $0.005^{*}$ \\
\hline $\begin{array}{l}\text { Regional Strain of } \\
\text { Apical } 4 \text { view }\end{array}$ & $-15.23 \pm 3.28$ & $-19.68 \pm 2.49$ & 35.944 & $0.001^{*}$ \\
\hline \multicolumn{5}{|l|}{ Apical 2 view } \\
\hline $\begin{array}{l}\text { Longitudinal Strain INF } \\
\text { wall }\end{array}$ & $-15.09 \pm 3.68$ & $-19.69 \pm 3.29$ & 4.51 & $0.001^{\star}$ \\
\hline $\begin{array}{l}\text { Longitudinal Strain of } \\
\text { ANT wall }\end{array}$ & $-14.92 \pm 3.66$ & $-20.45 \pm 2.68$ & 5.78 & $0.001^{*}$ \\
\hline $\begin{array}{l}\text { Regional Strain of } \\
\text { Apical } 2 \text { view }\end{array}$ & $-15.00 \pm 3.28$ & $-20.07 \pm 2.49$ & 35.944 & $0.001^{*}$ \\
\hline \multicolumn{5}{|l|}{ Apical 3 view } \\
\hline $\begin{array}{l}\text { Longitudinal Strain of } \\
\text { ANTSEP wall }\end{array}$ & $-14.89 \pm 4.6$ & $-20.76 \pm 3.4$ & 4.87 & $0.001^{*}$ \\
\hline $\begin{array}{c}\text { Longitudinal Strain of } \\
\text { POST wall }\end{array}$ & $-14.82 \pm 5.9$ & $-21.08 \pm 4.36$ & 4.06 & $0.002^{*}$ \\
\hline $\begin{array}{l}\text { Regional Strain of } \\
\text { Apical } 3 \text { view }\end{array}$ & $-14.86 \pm 3.28$ & $-20.92 \pm 2.49$ & 35.944 & $0.001^{*}$ \\
\hline $\begin{array}{c}\text { Global Longitudinal } \\
\text { Strain }\end{array}$ & $-15.05 \pm 3.28$ & $-20.22 \pm 2.49$ & 35.944 & $0.001^{*}$ \\
\hline $\begin{array}{c}\text { Global } \\
\text { Circumferential Strain }\end{array}$ & $19.88 \pm 8.63$ & $-21.93 \pm 5.69$ & 10.294 & 0.07 \\
\hline Global Radial Strain & $29.75 \pm 18.26$ & $28.09 \pm 15.48$ & 0.112 & 0.740 \\
\hline
\end{tabular}

These findings can be explained by the fact that myocardial blood supply is segmental and microvascular dysfunction has a patchy distribution in the myocardial wall rather than a diffuse distribution. Thus, normally functioning segments with normal blood supply may compensate and easily obscure the effect imposed by the affected segments on the LV function. The routine 2-D echocardiographic measurements of LV functions assess the global hemodynamic function rather than the LV segmental, regional and global mechanical function in addition to being subjective, operator and load dependent that is why they are less sensitive. Doppler tissue imaging assesses LV mechanical function but it suffers major disadvantages as angle dependence, limited spatial resolution, and deformation analysis in one dimension [11].

Using speckle tracking imaging based strain and strain rate, our study reported impaired systolic function proved by significantly lower global and regional 
M. Kamel et al.

Table 5. Comparison of LV strain rate between studied groups.

\begin{tabular}{|c|c|c|c|c|c|}
\hline \multicolumn{2}{|l|}{ Strain Rate } & $\begin{array}{c}\text { Case } \\
\text { Mean } \pm \text { S.D }\end{array}$ & $\begin{array}{c}\text { Control } \\
\text { Mean } \pm \text { S.D }\end{array}$ & t. test & $\begin{array}{c}\mathrm{p} . \\
\text { value }\end{array}$ \\
\hline \multicolumn{6}{|l|}{ Apical 4 view } \\
\hline \multirow{3}{*}{$\begin{array}{l}\text { Strain Rate } \\
\text { of Septal wall }\end{array}$} & S wave & $-1.08 \pm 0.27$ & $-1.36 \pm 0.36$ & 3.0814 & $0.003^{*}$ \\
\hline & E wave & $1.16 \pm 0.4$ & $1.88 \pm 0.55$ & 5.2631 & $0.001^{*}$ \\
\hline & A wave & $1.05 \pm 0.22$ & $0.96 \pm 0.47$ & 0.640 & 0.328 \\
\hline \multirow{3}{*}{$\begin{array}{l}\text { Strain Rate of } \\
\text { Lateral wall }\end{array}$} & S wave & $-1.02 \pm 0.26$ & $-1.36 \pm 0.36$ & 3.1849 & $0.002^{*}$ \\
\hline & E wave & $1.17 \pm 0.4$ & $1.88 \pm 0.52$ & 5.4618 & $0.001^{*}$ \\
\hline & A wave & $1.01 \pm 0.24$ & $0.95 \pm 0.45$ & 0.643 & 0.325 \\
\hline \multirow{3}{*}{$\begin{array}{l}\text { Regional Strain Rate of } \\
\text { Apical } 4 \text { chambers view }\end{array}$} & S wave & $-1.05 \pm 0.41$ & $-1.36 \pm 0.35$ & 8.816 & $0.005^{*}$ \\
\hline & E wave & $1.17 \pm 0.39$ & $1.88 \pm 0.47$ & 5.9237 & $0.001^{*}$ \\
\hline & A wave & $1.03 \pm 0.23$ & $0.95 \pm 0.49$ & 0.765 & 0.386 \\
\hline \multicolumn{6}{|c|}{ Apical 2 chambers view } \\
\hline \multirow{4}{*}{ Strain Rate of Inferior wall } & S wave & $-1.08 \pm 0.25$ & $-1.36 \pm 0.35$ & 3.2891 & $0.001^{*}$ \\
\hline & E wave & $1.17 \pm 0.39$ & $1.9 \pm 0.5$ & 5.712 & $0.001^{*}$ \\
\hline & A wave & $1.00 \pm 0.28$ & $0.94 \pm 0.48$ & 0.647 & 0.201 \\
\hline & S wave & $-1.07 \pm 0.23$ & $-1.36 \pm 0.35$ & 3.456 & $0.001^{*}$ \\
\hline \multirow[t]{2}{*}{ Strain Rate of Anterior wall } & E wave & $1.18 \pm 0.39$ & $1.91 \pm 0.45$ & 6.0324 & $0.001^{*}$ \\
\hline & A wave & $1.06 \pm 0.23$ & $0.99 \pm 0.46$ & 0.640 & 0.310 \\
\hline \multirow{3}{*}{$\begin{array}{l}\text { Regional Strain Rate of } \\
\text { Apical } 2 \text { view }\end{array}$} & S wave & $-1.07 \pm 0.41$ & $-1.36 \pm 0.35$ & 8.816 & $0.005^{*}$ \\
\hline & E wave & $1.18 \pm 0.39$ & $1.91 \pm 0.47$ & 5.9237 & $0.001^{*}$ \\
\hline & A wave & $1.03 \pm 0.23$ & $0.97 \pm 0.49$ & 0.765 & 0.386 \\
\hline \multicolumn{6}{|c|}{ Apical 3 view } \\
\hline \multirow{4}{*}{ Strain Rate of ANTSEP wall } & S wave & $-1.05 \pm 0.24$ & $-1.36 \pm 0.34$ & 3.3792 & $0.001^{*}$ \\
\hline & E wave & $1.19 \pm 0.39$ & $1.93 \pm 0.44$ & 6.1844 & $0.001^{*}$ \\
\hline & A wave & $1.04 \pm 0.25$ & $0.95 \pm 0.49$ & 0.641 & 0.318 \\
\hline & S wave & $-1.08 \pm 0.23$ & $-1.36 \pm 0.34$ & 3.4164 & $0.001^{*}$ \\
\hline \multirow[t]{3}{*}{ Strain Rate of Posterior wall } & E wave & $1.19 \pm 0.39$ & $1.95 \pm 0.43$ & 6.3368 & $0.001^{*}$ \\
\hline & A wave & $1.02 \pm 0.27$ & $0.93 \pm 0.45$ & 0.645 & 0.310 \\
\hline & S wave & $-1.06 \pm 0.41$ & $-1.36 \pm 0.35$ & 8.816 & $0.005^{*}$ \\
\hline \multirow{2}{*}{$\begin{array}{l}\text { Regional Strain Rate of } \\
\text { Apical } 3 \text { view }\end{array}$} & E wave & $1.19 \pm 0.39$ & $1.94 \pm 0.47$ & 5.9237 & $0.001^{*}$ \\
\hline & A wave & $1.03 \pm 0.23$ & $0.94 \pm 0.49$ & 0.765 & 0.386 \\
\hline \multirow{3}{*}{$\begin{array}{l}\text { Global longitudinal } \\
\text { Strain Rate }\end{array}$} & S wave & $-1.03 \pm 0.41$ & $-1.37 \pm 0.35$ & 8.816 & $0.005^{*}$ \\
\hline & E wave & $1.18 \pm 0.39$ & $1.91 \pm 0.47$ & 5.9237 & $0.001^{*}$ \\
\hline & A wave & $1.03 \pm 0.23$ & $0.94 \pm 0.49$ & 0.765 & 0.386 \\
\hline \multirow{3}{*}{$\begin{array}{c}\text { Global Circumferential } \\
\text { Strain Rate }\end{array}$} & S wave & $-1.35 \pm 0.45$ & $-1.45 \pm 0.47$ & 0.640 & 0.428 \\
\hline & E wave & $1.45 \pm 0.79$ & $1.95 \pm 0.75$ & 4.997 & $0.030^{*}$ \\
\hline & A wave & $1.00 \pm 0.48$ & $0.84 \pm 0.38$ & 1.685 & 0.201 \\
\hline \multirow{3}{*}{$\begin{array}{l}\text { Global Radial } \\
\text { Strain Rate }\end{array}$} & S wave & $1.62 \pm 0.82$ & $1.36 \pm 0.96$ & 1.054 & 0.310 \\
\hline & E wave & $-1.61 \pm 0.82$ & $-0.41 \pm 1.77$ & 10.413 & $0.002^{*}$ \\
\hline & A wave & $-1.08 \pm 0.87$ & $-0.9 \pm 1.17$ & 6.232 & 0.116 \\
\hline
\end{tabular}

${ }^{\star}$ Significant, $\mathrm{P}$-value $\leq 0.05$ is considered significant, $\mathrm{t}=$ student test.

longitudinal strain and strain rate in patients with CSX compared to controls. These findings are concordant with the findings of Yagmur J. et al. They concluded 


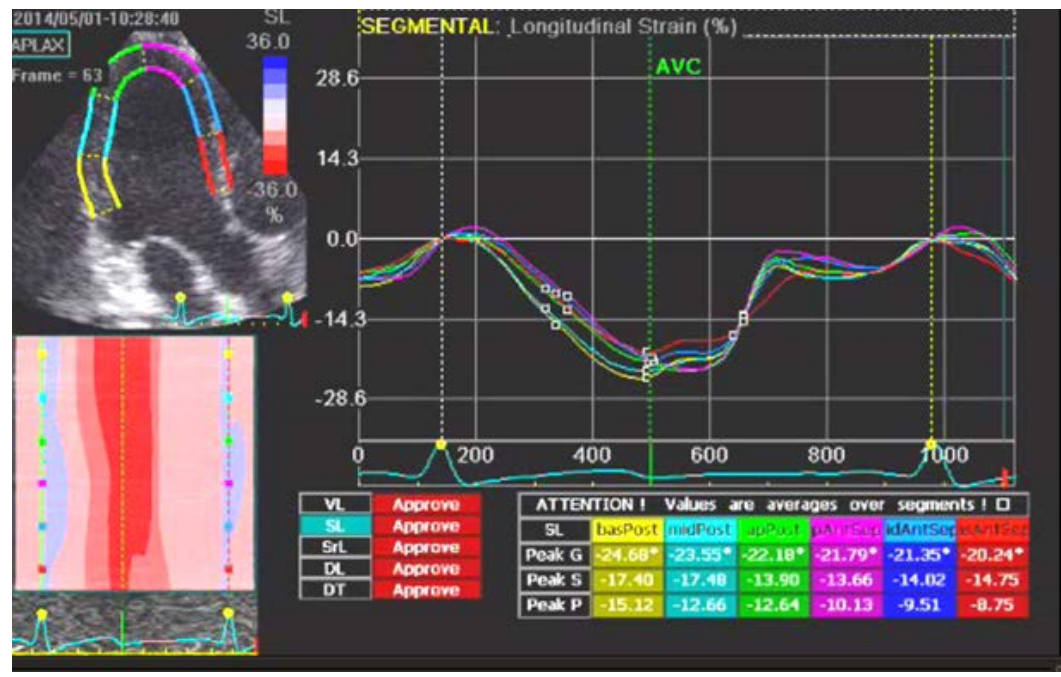

Figure 1. Apical long axis view showing the peak longitudinal strain.

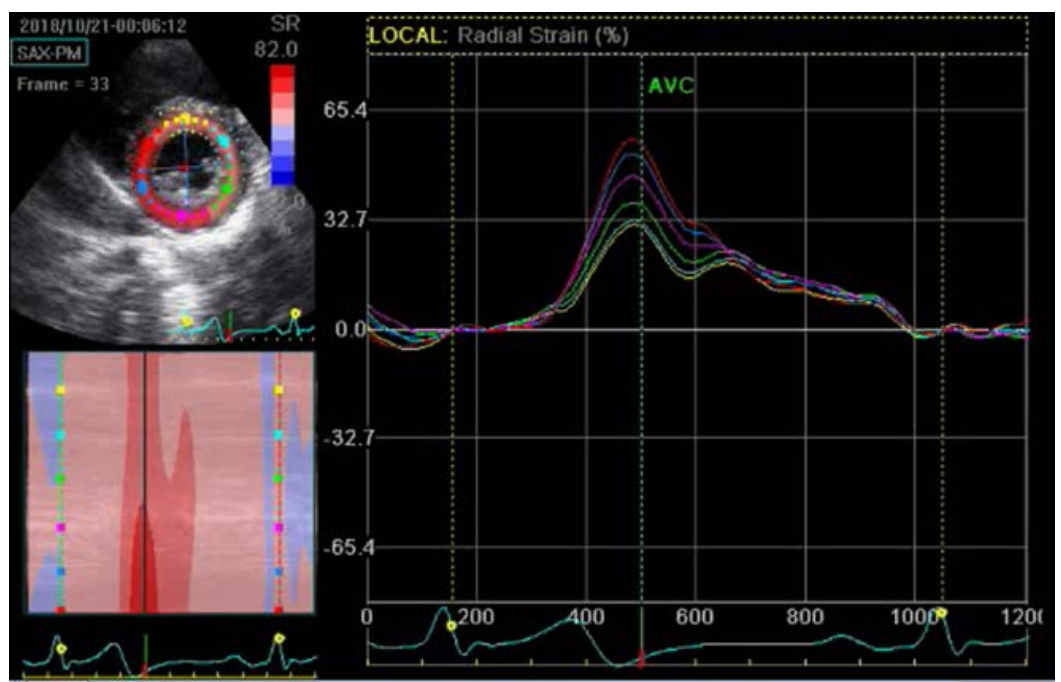

Figure 2. Short axis view demonstrating the radial strain.

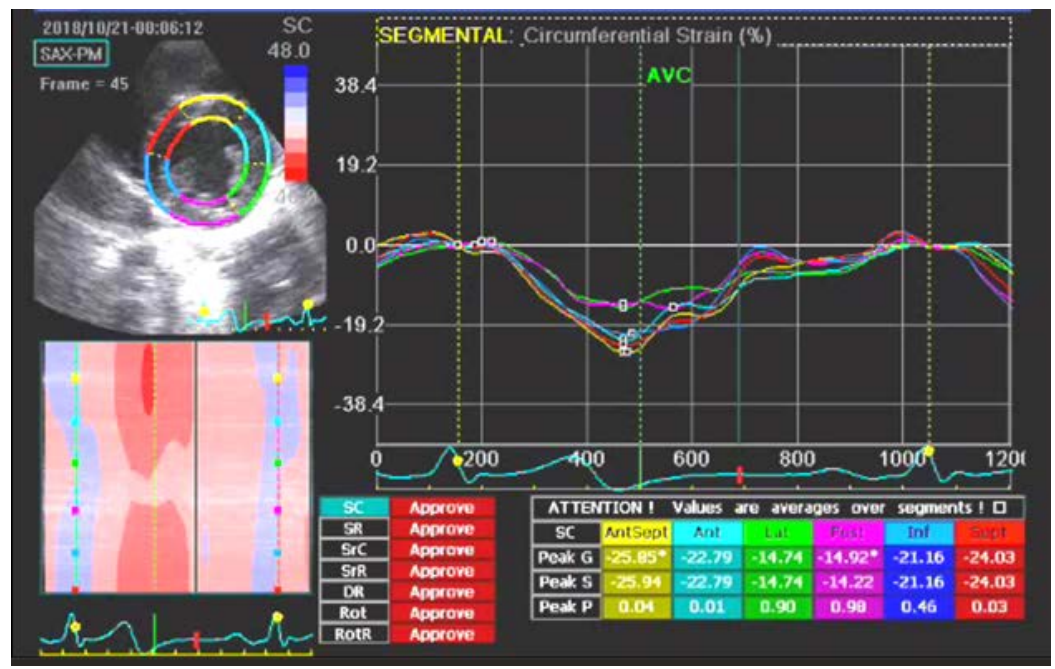

Figure 3. Short axis view showing the peak circumferential strain. 
that in spite of normal 3D derived EF and tissue Doppler imaging derived systolic parameters, patients with syndrome CSX have a significantly impaired LV longitudinal myocardial systolic function using speckle tracking imaging [12].

The same findings has been reported by Kaski J. Cwho used Doppler tissue imaging derived global longitudinal strain and strain rate to compare between 22 postmenopausal women with CSX and 20 healthy women. He found that patients with CSX showed a significantly lower value in GLS and SR compared to control group [13].

The sub-endocardium is unique in its susceptibility to disease processes. Its unique myocardial fiber orientation, anatomical position and susceptibility to marked pressure variation render it the harbinger of future overt cardiac dysfunction [14].

Panting et al. [6] used gadolinium cardiac magnetic resonance imaging with adenosine to study myocardial perfusion in patients with CSX. They provided supporting evidence for the presence of coronary microvascular dysfunction in CSX. They reported that there was a consistent evidence for an abnormality of myocardial perfusion limited to the sub-endocardial layer using this technique. These findings were compatible with the presence of sub-endocardial ischemia, despite the absence of LV wall motion abnormalities in a significant proportion of the patients with CSX.

Sun et al. [15] also showed that there was impairment in LV function in the follow-up of patients with CSX who had an abnormal thallium scan.

The presence of subendocardial ischemia in patients with microvascular angina leads to subendocardial dysfunction that could potentially affect ventricular longitudinal functions. As ventricular subendocardial fibers are predominantly longitudinal in orientation, and early manifestations of cardiac abnormalities are usually observed in the subendocardial layer [16].

These facts can explain why patients with CSX have significantly lower both regional and global longitudinal strain denoting subclinical affection of left ventricular systolic function.

With respect to LV short axis function, our data show that radial and circumferential stain and systolic strain rate did not differ significantly in both groups and this can be explained as the circumferential fibers are predominantly in the mid layer of myocardium [16]. Circumferential function has previously been shown to be caused by the mid myocardial circular fibers and it became affected later after subendocardial fiber affection during sub-endocardial (non-transmural), infarction with preserved both radial and circumferential function among those patients [17] [18].

Included patients were found to have diastolic dysfunction proved by Doppler tissue imaging and decreased global (longitudinal, circumferential and radial), E wave SR. Yazici, H. U., et al. [7], Moreno, R., et al. [8] using pulsed wave Doppler tissue imaging proved that patient with CSX suffered from regional diastolic function and concluded that that patients with CSX have impaired regional LV diastolic function despite normal EF. 
Diastolic dysfunction occurs early in the ischemic cascade. Nelson et al. [19] used cardiac MRI to evaluate diastolic function in 20 women with CSX with preserved LV ejection fraction. Several studies identified multiple abnormalities in diastolic function using tissue tagging analysis. Specifically, patients had lower diastolic circumferential strain rate, lower peak rate of left ventricular untwisting, and longer time to peak filling rate and peak ventricular untwisting rate, as well as a trend toward longer time to peak diastolic circumferential strain rate [20] [21] [22].

\section{Conclusion}

Speckle tracking echocardiography is a relatively new imaging modality that could provide early detection of subclinical mechanical myocardial affection. Speckle tracking echocardiographic derived global longitudinal strain and strain rate were found to be sensitive parameters for assessment of subclinical LV, both systolic and diastolic dysfunction in patients with CSX not detectable by conventional echocardiographic derived parameters. Being easy bedside noninvasive technique, it can be used for early detection of LV mechanical dysfunction and follow-up of patients with CSX.

\section{Limitations}

Study included small number of patient. There is the need for further studies with larger number of patients to verify the results. Also we did not examine the results according to the deference in sex as syndrome $\mathrm{X}$ is more common in female sex.

\section{Conflicts of Interest}

The authors declare no conflicts of interest regarding the publication of this paper.

\section{References}

[1] Cannon, R.O., Leon, M.B., Watson, R.M., Rosing, D.R. and Epstein, S.E. (1985) Chest Pain and "Normal" Coronary Arteries Role of Small Coronary Arteries. American Journal of Cardiology, 55, 50B60B.

[2] Cannon, R.O. and Epstein, S.E. (1988) "Microvascular Angina" as a Cause of Chest Pain with Angiographically Normal Coronary Arteries. American Journal of Cardiology, 61, 1338-1343. https://doi.org/10.1016/0002-9149(88)91180-0

[3] Arthur, H.M., Pat Campbell, R.N., Harvey, P.J., McGillion, M., Oh, P., Woodburn, E. and Hodgson, C. (2012) Women, Cardiac Syndrome X, and Microvascular Heart Disease. Canadian Journal of Cardiology, 28, S42-S49.

[4] Marroquin, O.C., Holubkov, R., Edmundowicz, D., Rickens, C., Pohost, G., Buchthal, S., et al. (2003) Heterogeneity of Microvascular Dysfunction in Women with Chest Pain Not Attributable to Coronary Artery Disease: Implications for Clinical Practice. American Heart Journal, 145, 628-635.

https://doi.org/10.1067/mhj.2003.95 
[5] Zeiher, A.M., Krause, T., Schachinger, V., Minners, J. and Moser, E. (1995) Impaired Endothelium-Dependent Vasodilation of Coronary Resistance Vessels Is Associated with Exercise-Induced Myocardial Ischemia. Circulation, 91, 2345-2352. https://doi.org/10.1161/01.CIR.91.9.2345

[6] Panting, J.R., Yang, G.Z., Grothues, F., Firmin, D.N., Collins, P., et al. (2002) Abnormal Subendocardial Perfusion in Cardiac Syndrome X Detected by Cardiovascular Magnetic Resonance Imaging. The New England Journal of Medicine, 346, 1948-1953. https://doi.org/10.1056/NEJMoa012369

[7] Yazici, H.U., Şen, N., Tavil, Y., Hizal, F., Turfan, M., Poyraz, F., et al. (2009) Left Ventricular Functions in Patients with Cardiac Syndrome X: A Tissue Doppler Study. The Anatolian Journal of Cardiology, 9, 467-472.

[8] Moreno, R., Garcia-Fernandez, M.A., Moreno, M., Puerta, P., Bermejo, J., Ortega, A., et al. (1999) Regional Diastolic Function in Microvascular Angina Studied by Pulsed-Wave Doppler Tissue Imaging. Echocardiography, 16, 239-244. https://doi.org/10.1111/j.1540-8175.1999.tb00808.x

[9] Gorcsan III, J. and Tanaka, H. (2011) Echocardiographic Assessment of Myocardial Strain. Journal of the American College of Cardiology, 58, 1401-1413. https://doi.org/10.1016/j.jacc.2011.06.038

[10] Mor-Avi, V., Lang, R.M., Badano, L.P., Belohlavek, M., Cardim, N.M., Derumeaux, G., et al. (2011) Current and Evolving Echocardiographic Techniques for the Quantitative Evaluation of Cardiac Mechanics: ASE/EAE Consensus Statement on Methodology and Indications Endorsed by the Japanese Society of Echocardiography. Journal of the American Society of Echocardiography, 24, 277-313. https://doi.org/10.1016/j.echo.2011.01.015

[11] Maseri, A., Crea, F., Kaski, J.C. and Crake, T. (1991) Mechanisms of Angina Pectoris in Syndrome X. Journal of the American College of Cardiology, 17, 499-506. https://doi.org/10.1016/S0735-1097(10)80122-6

[12] Yağmur, J., Açıkgöz, N., Cansel, M., Ermiş, N., Karakuş, Y. and Kurtoğlu, E. (2016) Assessment of the Left Ventricular Systolic Function in Cardiac Syndrome X Using Speckle Tracking Echocardiography. The Anatolian Journal of Cardiology, 16, 419-423.

[13] Kaski, J.C. (2006) Cardiac Syndrome X in Women: The Role of Oestrogendeficiency. Heart, 92, iii5-iii9. https://doi.org/10.1136/hrt.2005.070318

[14] Stanton, T. and Marwick, T.H. (2010) Assessment of Subendocardial Structure and Function. JACC: Cardiovascular Imaging, 3, 867-875. https://doi.org/10.1016/j.jcmg.2010.05.011

[15] Sun, S.S., Huang, J.L., Tsai, S.C., Ho, Y.J. and Kao, C.H. (2001) The Higher Likelihood of Developing Cardiomegaly during Follow-Up in Patients with Syndrome X and Abnormal Thallium-201 Myocardial Perfusion SPECT. The International Journal of Cardiovascular Imaging, 17, 271-278. https://doi.org/10.1023/A:1011661300903

[16] Greenbaum, R.A., Ho, S.Y., Gibson, D.G., Becker, A.E. and Anderson, R.H. (1981) Left Ventricular Fibre Architecture in Man. British Heart Journal, 45, 248-263. https://doi.org/10.1136/hrt.45.3.248

[17] Zhang, Y., Chan, A.K., Yu, C.M., et al. (2005) Strain Rate Imaging Differentiates Transmural from Non-Transmural Myocardial Infarction a Validation Study Using Delayed-Enhancement Magnetic Resonance Imaging. Journal of the American College of Cardiology, 46, 864-871. https://doi.org/10.1016/j.jacc.2005.05.054

[18] Garot, J., Bluemke, D.A., Osman, N.F., et al. (2000) Transmural Contractile Reserve 
after Reperfused Myocardial Infarction in Dogs. Journal of the American College of Cardiology, 36, 2339-2346. https://doi.org/10.1016/S0735-1097(00)00992-X

[19] Nelson, M.D., Szczepaniak, L.S., Wei, J., Haftabaradaren, A., Bharadwaj, M., Sharif, B., Mehta, P., Zhang, X., Thomson, L.E., Berman, D.S., Li, D. and BaireyMerz, C.N. (2014) Diastolic Dysfunction in Women with Signs and Symptoms of Ischemia in the Absence of Obstructive Coronary Artery Disease: A Hypothesis-Generating Study. Circulation: Cardiovascular Imaging, 7, 510-516. https://doi.org/10.1161/CIRCIMAGING.114.001714

[20] Pai, V.M. and Axel, L. (2006) Advances in MRI Tagging Techniques for Determining Regional Myocardial Strain. Current Cardiology Reports, 8, 53-58. https://doi.org/10.1007/s11886-006-0011-4

[21] Wang, J., Khoury, D.S., Yue, Y., Torre-Amione, G. and Nagueh, S.F. (2008) Preserved Left Ventricular Twist and Circumferential Deformation, But Depressed Longitudinal and Radial Deformation in Patients with Diastolic Heart Failure. European Heart Journal, 29, 1283-1289. https://doi.org/10.1093/eurheartj/ehn141

[22] Flett, A.S., Hayward, M.P., Ashworth, M.T., Hansen, M.S., Taylor, A.M., Elliott, P.M., McGregor, C. and Moon, J.C. (2010) Equilibrium Contrast Cardiovascular Magnetic Resonance for the Measurement of Diffuse Myocardial Fibrosis: Preliminary Validation in Humans. Circulation, 122, 138-144. https://doi.org/10.1161/CIRCULATIONAHA.109.930636 